\title{
The Prevalence of Alcohol Consumption and Common Influencing Factors to Start Alcohol Consumption in Early Age: Health Fair Study in Dominica
}

\section{Olamide Olayinka ${ }^{1}$, Uchenna Ozoekwe ${ }^{2}$, Chidambra D Halari ${ }^{3}$, Moheem Halari ${ }^{3}$, Oluwaseyi Joy Alao ${ }^{2}$, Temiloluwa Oladoyin Ige ${ }^{2}$ and Srinivas Medavarapu ${ }^{3 *}$}

${ }^{1}$ Basic Sciences, All Saints University School of Medicine, Roseau, Dominica

${ }^{2}$ Clinical Sciences, All Saints University School of Medicine, Roseau, Dominica

${ }^{3}$ All Saints University School of Medicine, Roseau, Dominica

${ }^{*}$ Corresponding author: Srinivas Medavarapu, Assistant Professor, All Saints University School of Medicine, Roseau, Dominica, Tel: 18483915130; Email: srinivasmedavarapu@yahoo.co.in

Received date: October 28, 2016; Accepted date: November 04, 2016; Published date: November 11, 2016

Citation: Olayinka O, Ozoekwe U, Halari CD, Halari M, Alao OJ, et al. The Prevalence of Alcohol Consumption and Common Influencing Factors to Start Alcohol Consumption in Early Age: Health Fair Study in Dominica. Arch Med. 2016, 8:6

Copyright: (c) 2016 Olayinka O, et al. This is an open-access article distributed under the terms of the Creative Commons Attribution License, which permits unrestricted use, distribution, and reproduction in any medium, provided the original author and source are credited.

\section{Abstract}

Background: Alcohol is one of the most widely used recreational drugs in the world however, over the last decade its consumption has become an increasing concern along public health policy makers and international development agencies. The Caribbean populace particularly has in recent times had challenges from alcohol abuse which has posed significant morbidity and mortality of all age groups. This research has its focus on alcohol consumption among young adults using Dominica as case study.

Aim of the study: To determine the prevalence of alcohol consumption in young adults in Dominica. Also, to determine the common reasons and influencing factors to start alcohol consumption in younger age groups in Dominica.

Methods and Findings: A total of 73 respondents from the city of Roseau and its neighbouring villages who attended a health fair organised in All Saints University School of Medicine, Roseau, Dominica. The research was a cross sectional study that involved use of a questionnaire for the collection of data. The findings showed that $66.67 \%$ consumed alcohol with majority of them being males (73.91\%). Onset for consumption was higher in the age group 16-20 years with reasons being: peer pressure, social activities, curiosity and adult influence. Again, the age group $16-20$ years had the highest onset for alcohol consumption giving major reason of social activity $(71.43 \%)$.

Conclusion: The study showed that most common age to start consuming alcohol was between $16-20$ years and common reasons to start included 'social activities' and 'peer pressure' for majority and for a few 'curiosity' and 'adult influence'. It becomes incumbent on the government, healthcare practitioners and other stakeholders to promote responsible drinking and discourage premature drinking. In conclusion, applying regression analysis, age is a predictor of alcohol consumption and for each unit increase in age, there is an average increase of $13 \%$ in alcohol consumption considering a constant gender among Dominicans.

Keywords: Alcohol; Alcohol consumption; Caribbean; Premature drinking; Peer pressure; Social activities; Adult influence; Curiosity; Age; Gender

\section{Introduction}

Alcohol consumption is a regular and historical habit in many societies and as a part of their diet. Alcohol has a very deep and close association with the Caribbean region historically as well as being part of its culture, the Caribbean being known a major producer of rum and sugar cane. Over the years it has been a vigorous task to distinguish between social alcohol consumption and when it becomes a dependence or excessive intake. Previous literature reviews have significantly pointed out the signs and symptoms to give a dependence diagnosis or excessive drinking.

Alcoholism is defined as a medical condition in which someone frequently drinks too much alcohol and becomes unable to live a normal and healthy life [1]. It is characterised by the inability to control drinking once it has begun, physical dependence manifested by withdrawal symptoms when the individual stops using alcohol, tolerance, or the need to use more and more alcohol to achieve the same effects [1].

The legal age for alcohol consumption varies from country to country referred to as minimum legal drinking age (MLDA) and is based on 'on premise purchase age' and 'off premise purchase age' this is stated according to 'Global Status Report on Alcohol and Health'. It is indicated that MLDA ranging from 18-25 years for India, 21 years in countries like USA and 18-19 years in most countries [2]. According to the same document, Dominica's MLDA is 16 years, whereas the legal age of majority which is a 
legal acknowledgement that one has attained adulthood is 18 years $[3,4]$.

Compared to about $171 / 2$ in 1965 , average resumption of alcohol use was 14 in 2003 with male average 13.8 and female 14.2 [5]. Abuse of substances attains peak levels during late adolescence and early part of adulthood then reduces later [6].

Alcoholism is more common in males than in females while cumulative abstinence is more common among females than males [6] due to cultural in addition to biological factors [7]. Attributes such as risk taking, expectancies, sensitivity and tolerance to alcohol, personality characteristics and psychiatric comorbidities, hereditary factors, environmental aspects among adolescents have been pointed as reasons for resumption of alcohol consumption [8].

Alcohol abuse is seen as a global issue and excessive consumption of alcohol have posed significant morbidity and mortality worldwide [9]. Approximately 3.3 million deaths worldwide in 2012 were estimated to have been caused by alcohol consumption. This statistics corresponds to $5.9 \%$ of all deaths, or one in every twenty deaths in the world $[9,10]$.

Drinking alcohol is associated with a risk of developing such health problems as alcoholism, liver cirrhosis, cancers and injuries [11-13]. Relationships suggested by research findings links alcohol consumption and incidence of infectious diseases such as tuberculosis and HIV/AIDS [14-16] as well as between the harmful use of alcohol during the course of HIV/AIDS $[17,18]$

\section{Materials and Method}

Study area: All Saints University School of Medicine is located in Roseau, Commonwealth of Dominica. The Island is one of the Windward Islands in the Eastern Caribbean, lying between Guadeloupe to the north and Martinique to the south. Its area is $750 \mathrm{~km}^{2}$ with a population density of 96 per $\mathrm{km}^{2}$.

Study population: The projected population of Dominica is 73,600 .

Study design: The study design is cross-sectional.

Sampling: Convenience sample of 73 respondents from health fair conducted in All Saints University School of Medicine.

Inclusion criteria: All citizens of Commonwealth of Dominica.

Exclusion criteria: Non-citizens of Commonwealth of Dominica.

Data collection: A self-administered questionnaire was administered. The questionnaire was pretested within the school premises. The questionnaire assessed variables including demographic data, onset of alcohol consumption, and motivation for alcohol consumption and addition four questions that represented the CAGE questions. The volunteers were supervised by the professor responsible to the research team.
Data analysis: The data obtained were entered into microsoft excel package and screened. Analysis was done using StatalC. Data are presented in the form of frequencies and percentages.

\section{Results}

A total of 73 subjects participated in the research. They consist of both 23 (31.5\%) males and 50 (68.5\%) females. Among them, $66.67 \%$ reported that they consume alcohol, while $33.33 \%$ reported they don't consume alcohol.

$73.91 \%$ of males reported that they consume alcohol while $26.09 \%$ reported they don't consume alcohol. $63.27 \%$ of females reported that they consume alcohol while $36.73 \%$ of them reported they don't consume alcohol.

The age range of the respondents was between $<10$ years to $>45$ years. $40.38 \%$ of males were $>45$ years, $15.38 \%$ were aged $26-45$ years. For the females, $59.62 \%$ were $>45$ years, $84.62 \%$ were $26-45$ years.

Males reported they began to consume alcohol at $<10$ years (6.25\%), $11-15$ years $(6.25 \%), 16-20$ years $(81.25 \%)$, and $21-30$ years $(6.25 \%)$. The females reported they began to consume alcohol at $<10$ years $(10.71 \%), 11-15$ years $(7.14 \%), 16-20$ years (60.71\%), $21-30$ years ( $21.43 \%)$.

Table 1 shows the onset of alcohol consumption based on age group. $33.33 \%$ and $66.67 \%$ of recipients started drinking $<10$ years and between $11-15$ years respectively.

$75 \%$ started drinking between $16-20$ years, for the age groups; 21-25 years and $26-45$ years. $72.41 \%$ started drinking between $16-20$ years showing for the age group $>45$ years.

Table 1 Comparison of current age groups based on the age people started alcohol consumption.

\begin{tabular}{|l|l|l|l|l|}
\hline $\begin{array}{l}\text { Current } \\
\text { (years) }\end{array}$ & age & \multicolumn{4}{|c|}{ Age people started alcohol consumption n (\%) } \\
\hline & $\begin{array}{l}<10 \\
\text { years }\end{array}$ & $\begin{array}{l}11-15 \\
\text { years }\end{array}$ & $\begin{array}{l}16-20 \\
\text { years }\end{array}$ & $\begin{array}{l}21-30 \\
\text { years }\end{array}$ \\
\hline $10-20$ years & 33.33 & 66.67 & 0.00 & 0.00 \\
\hline $21-25$ years & 25.00 & 0.00 & 75.00 & 0.00 \\
\hline $26-45$ years & 12.5 & 0.00 & 75.00 & 12.50 \\
\hline$>45$ years & 3.45 & 6.90 & 72.41 & 17.24 \\
\hline
\end{tabular}

$25 \%$ and $75 \%$ of participants below 10 years started alcohol consumption due to adult influence and social activity respectively. $33.33 \%$ and $66.67 \%$ in the age group $11-15$ years started alcohol consumption due to peer pressure and social activity.

$70.00 \%$ in the age group 16-20 years had reasons for onset of alcohol consumption as social activity. $71.43 \%$ in the age group 21-30 years had reason for onset of alcohol consumption also on 
social activity with a few of them giving reasons of peer pressure and adult influence (Table 2 ).

Table 2 Reason for early age onset of alcohol consumption.

\begin{tabular}{|l|l|l|l|}
\hline \multirow{2}{*}{ Age people started alcohol consumption } & \multicolumn{3}{|c|}{ Reason to start alcohol consumption $\mathbf{n}(\%)$} \\
\cline { 2 - 4 } & Peer pressure & Curiosity & Influence of an adult \\
\hline$<10$ years & 0.00 & 0.00 & 25.00 \\
\hline $11-15$ years & 33.33 & 0.00 & 0.00 \\
\hline $16-20$ years & 10.00 & 10.00 & 10.00 \\
\hline $21-30$ years & 14.29 & 0.00 & 70.00 \\
\hline
\end{tabular}

$33.33 \%$ and $66.67 \%$ of the respondents aged $10-20$ years consumed alcohol due to influence of an adult and social activity respectively. $25 \%$ and $75 \%$ of the respondents aged $21-25$ years consumed alcohol due to influence of an adult and social activity respectively. $20 \%$ and $80 \%$ of the respondents aged $26-45$ years consumed alcohol due to influence of an adult and social activity respectively, whereas $16.13 \%, 12.90 \%, 3.23 \%, 64.52 \%$ of the respondents aged $>45$ years consumed alcohol due to peer pressure, curiosity, influence of an adult and social activity respectively. $3.23 \%$ of respondents aged $>45$ years reported nil alcohol consumption (Table 3).

Table 3 Comparison on current age groups and reason of alcohol consumption.

\begin{tabular}{|l|l|l|l|l|l|}
\hline Current age (years) & $\begin{array}{l}\text { 'YES' to consumption of alcohol } \mathbf{n} \\
\text { (\%) }\end{array}$ & $\begin{array}{l}\text { Peer pressure } \\
\mathbf{n}(\%)\end{array}$ & $\begin{array}{l}\text { Curiosity } \\
\mathbf{n}(\%)\end{array}$ & $\begin{array}{l}\text { Adult influence } \\
\mathbf{n}(\%)\end{array}$ & $\begin{array}{l}\text { Social activity } \\
\mathbf{n}(\%)\end{array}$ \\
\hline $10-20$ years & 75 & 0.00 & 0.00 & 33.33 & 66.67 \\
\hline $21-25$ years & 100 & 0.00 & 0.00 & 25.00 & 75.00 \\
\hline $26-45$ years & 76.92 & 0.00 & 0.00 & 20.00 & 80.00 \\
\hline$>45$ years & 60.78 & 16.13 & 12.90 & 3.23 & 64.52 \\
\hline
\end{tabular}

A total of $27.0 \%$ of the respondents were positive for CAGE questionnaire while $72.92 \%$ were negative for CAGE questionnaire. Thus, $35.29 \%$ of males were positive for CAGE questionnaire, while $64.71 \%$ were negative for CAGE questionnaire. For the females, $22.58 \%$ were positive for CAGE questionnaire while $77.42 \%$ were negative for CAGE questionnaire. Among the respondents who reported that they have consumed alcohol, $27.66 \%$ were positive for CAGE questionnaire while $72.34 \%$ were negative for CAGE questionnaire (Table 4).

Table 4 Comparison on gender and reason of alcohol consumption, CAGE positive (addiction).

\begin{tabular}{|l|l|l|l|l|l|}
\hline Gender & $\begin{array}{l}\text { Consumption of } \\
\text { Alcohol } \\
\mathbf{n}(\%)\end{array}$ & $\begin{array}{l}\text { CAGE Question Positive } \\
\mathbf{n}(\%)\end{array}$ & $\begin{array}{l}\text { Peer } \\
\text { Pressure } \\
\mathbf{n}(\%)\end{array}$ & $\begin{array}{l}\text { Adult } \\
\text { Influence } \\
\mathbf{n}(\%)\end{array}$ \\
\hline Male & 73.91 & 35.29 & 23.53 & 5.88 \\
$\mathbf{n}(\%)$ \\
\hline Female & 63.27 & 22.58 & 3.23 & 5.88 \\
\hline
\end{tabular}

The respondents reported that peer pressure, curiosity, influence of adults, social activity were the reasons why $10.42 \%$, $8.33 \%, 10.42 \%, 68.75 \%$, consumed alcohol respectively, whereas $2.08 \%$ reported nil alcohol consumption. For the males, peer pressure, curiosity, influence of adults, social activity were the reasons why $23.53 \%, 5.88 \%, 5.88 \%, 58.82 \%$ consumed alcohol respectively, while another $5.88 \%$ reported nil alcohol consumption. For the females, peer pressure, curiosity, influence of adults, social activity were the reasons why $3.23 \%, 9.68 \%$, $12.90 \%, 74.19 \%$ consumed alcohol respectively (Table 4 ).

\section{Discussion}

Globally previous studies have shown a higher percentage of alcohol intake in males compared to their female counterparts and this study has not shown otherwise. This can be attributed to the different aging or stages of adult life affect drinking patterns similarly or differently for men and women [19]. This study confirms that there is higher rate of alcohol consumption and dependence among men compared to women. Most of the recipients started consuming alcohol within the ages of 16-20 years with reasons of consuming alcohol ranging from peer 
pressure to a sense of belonging and due to their new found independence. Similarly, a study carried out by Olaosebikan et al. [20] described the effect of peer pressure on alcohol drinking among some single women suggesting that under the influence of alcohol, individuals were predisposed to violence and antisocial behavior, unplanned sexual activity and the related problem of sexually transmitted infections, stating that societal trends in alcohol consumption and social harm are likely to increase alongside one another. However, the women in this study attributed their reasons for alcohol consumption majorly to curiosity, influence from adults and social activities.

Again, a good number of participants gave reasons for alcohol drinking and indeed early onset of alcohol drinking on social activities including parties, fraternity or sorority affiliation which is also in correlation with past research work. In a research carried out by McCabe et al. [21], it was suggested that individuals who were social; belonging to clubs, organization, partying etc. were prone to be heavier drinkers as compared to those who were not as social.

Alcohol consumption is one of the most widely abused substances globally producing variety of effects on the human body and these effects varies by gender. Studies have shown that alcohol use is related detrimentally too many cardiovascular problems, including hypertension, hemorrhagic stroke and atrial fibrillation [22]. Consumption of alcohol has also been implicated in other conditions like cancers, fetal alcohol syndrome and diabetes mellitus [23]. Alcohol worsens the course of HIV/AIDS and increases susceptibility to infectious diseases [23].

Alcohol intake has been attributed to over 1.8 million mortalities [24] with lifetime prevalence among Caribbean amounting to $68.90 \%$ [25]. With the growing global concern of the increasing rate of alcohol abuse, this study compares various factors associated with alcohol consumption such as gender differentiation and tendency to addiction, life span variation in consumption, social and cultural reasons for its consumption amongst young adults in Dominica. Therefore, the factors associated with alcohol abuse identified in this study in the order of increasing prevalence are: peer pressure, curiosity, influence from adults, and social activities. One reason why some people do not age out of heavy episodic drinking may be that in some cultures drinking traditionally is a privilege or obligation associated with higher status or seniority [24].

In a study by Seaman and Ikegwuonu [24] some factors responsible for excessive drinking among young adults include; the fact that alcohol had an important cultural role in offering one of the few occasions in their lives for fun making, maintaining friendships and group bonding. Also, young adults did not worry about the health risks of alcohol, recognizing their drinking as part of the normal experience of young adulthood and therefore temporary.

Mothers who consume alcohol during pregnancy risk serious harm to their unborn infants. The range of effects that can occur is known as fetal alcohol spectrum disorder (FASD) and it includes physical, mental, behavioral and or learning disabilities, possibly with lasting complications. FASD is comprised of fetal alcohol syndrome (FAS), alcohol related neurodevelopmental disorder (ARND), fetal alcohol effects (FAE), and alcohol related birth defects (ARBD). Velleman [26] linked alcohol consumption to physical, verbal, sexual abuse of children by parents leading to psychological and behavioural disturbance among children. Grant et al. [27] believed that significant alcohol intake by individuals produces changes in the brain's structure and chemistry, though some alterations occur with minimal use of alcohol over a short time period, such as tolerance and physical dependence. These changes maintain the person with compulsive inability to stop drinking alcohol and results to alcohol withdrawal syndrome if the person stops. Alcoholism reduces a person's life expectancy by around ten years [28] and alcohol use is the third leading cause of early death in the United States. There is greater risk in younger people due to binge drinking which may result in violence or accidents [29].

Constraints of this study were particularly in the method of data collection. Questionnaires were standardised so it was not possible to explain any points in the questions that participants might misinterpret.

Again, a constraint encountered was in the provision of false answers by recipients in which a number of them did not wish to reveal the information or did not think that they will not benefit from responding perhaps even be penalised or socially rejected by giving their real opinion [30,31].

\section{Conclusion and Recommendation}

The study showed that the common age to start consumption of alcohol was between 16-20 years and common reasons to start were peer pressure and social activities hence, it becomes incumbent on the government, healthcare practitioners and other stakeholders to promote responsible drinking and discourage premature drinking.

Since social activities as far as they meet legal provisions may not be stopped but being an available means or source of alcohol consumption promotion, it calls for a need to put certain controls methods on attendance and substance use of not just alcohol but other substances.

In conclusion, applying regression analysis, age is a predictor of alcohol consumption and for each unit increase in age, there is an average increase of $13 \%$ in alcohol consumption considering a constant gender among Dominicans.

\section{Acknowledgement}

Corresponding author would like to thank Silas Abiodun, Nancy Olumide for their contributions.

\section{References}

1. http://medical-dictionary.thefreedictionary.com/alcoholism

2. www.iard.org/policy-tables/minimum-legal-age-limits/

3. Cornick MS(1995) A practical guide to family law.

4. Citizens Information Board (2010) At what age can I? 
5. Newes-Adeyi G, Chen CM, Williams GD, Faden VB (2005) Surveillance report\#74: Trends in underage drinking in the United States, 1991-2003.

6. Wilsnack RW, Wilsnack SC, Kristjanson AF, Vogeltanz-Holm ND, Gmel G (2009) Gender and alcohol consumption: patterns from the multinational GENACIS project. Addiction 104: 1487-1500.

7. Wilsnack RW, Vogeltanz ND, Wilsnack SC, Harris TR, Ahlström S, et al. (2000) Gender differences in alcohol consumption and adverse drinking consequences: Cross-cultural patterns. Addict 95: 251-265.

8. http://pubs.niaaa.nih.gov/publications/AA67/AA67

9. WHO (2009) Global health risks: mortality and burden of disease attributable to selected major risks.

10. http://www.niaaa.nih.gov/alcohol-health/alcohols-effects-body. Retrieved 2014-11-25

11. Baan R, Straif K, Grosse Y, Secretan B, El Ghissassi F, et al. (2007) WHO International Agency for Research on Cancer Monograph Working Group. Carcinogenicity of alcoholic beverages. Lancet Oncol 8: 292-293.

12. Shield KD, Parry C, Rehm J (2013) Chronic diseases and conditions related to alcohol use. Alcohol Res 35: 155-173.

13. http://www.who.int/substance_abuse/publications/ global_alcohol_report/msb_gsr_2014_1.pdf

14. Lönnroth K, Williams BG, Stadlin S, Jaramillo E, Dye C (2008) Alcohol use as a risk factor for tuberculosis-a systematic review. BMC Public Health 8: 289.

15. Rehm J, Mathers C, Popova S, Thavorncharoensap M, Teerawattananon Y, et al. (2009) Global burden of disease and injury and economic cost attributable to alcohol use and alcoholuse disorders. Lancet 373: 2223-2233.

16. Baliunas D, Rehm J, Irving H, Shuper P (2010) Alcohol consumption and risk of incident human immunodeficiency virus infection: a meta-analysis Int Journal of Public Health 55: 159-166.

17. Hendershot CS, Stoner SA, Pantalone DW, Simoni JM (2009) Alcohol use and antiretroviral adherence: review and metaanalysis. J Acquir Immune Defic Syndr 52: 180-202.

18. Azar MM, Springer AS, Myer PJ (2010) A Systematic Review of the Impact of Alcohol Use Disorders on HIV Treatment Outcomes, Adherence to Antiretroviral Therapy and Health Care Utilization Published Drug Alcohol Depend. 112: 178-193.
19. Wilsnack, Richard W (2009) Gender and Alcohol Consumption: Patterns from the Multinational GENACIS Project. Addict 104: 1487-1500.

20. Olaosebikan OI, Osarenren NA, Okoli CE (2014) Peer Pressure and Disposition to Alcohol Drinking Among Some Single Women in Somolu Local Government Area of Lagos State, Nigeria. OSR Journal Res \& Met Edu 4: 15-23.

21. Parry, Charles D, Jayadeep Patra, Jürgen Rehm (2011) Alcoho Consumption and Non-Communicable Diseases: Epidemiology And Policy Implications. Addict 106: 1718-1724.

22. Gowing LR, Ali RL, Allsop S, Marsden J, Turf EE, et al. (2015) Global statistics on addictive behaviours: 2014 status report. Addiction 110: 904-919.

23. Litvak E, Foster KR, Repacholi MH (2002) Health and safety implications of exposure to electromagnetic fields in the frequency range $300 \mathrm{~Hz}$ to $10 \mathrm{MHz}$. Bioelectromag 23: 68-82.

24. Seaman P, Ikegwuonu T (2010) Drinking to belong Understanding young adults' alcohol use within social networks. Joseph Rowntree Foundation.

25. Valleman R (2002) The children of problem drinking parents. An executive summary series; centre for research on drug and health behaviour.

26. Grant BF, Dawson DA, Stinson FS, Chou SP, Dufour MC, et al. (2004) The 12-month prevalence and trends in DSM-IV alcohol abuse and dependence: United States, 1991-1992 and 2001-2002. Drug Alc Depend 74: 223-234.

27. Halari M, Adeiza O, Olumide N, Marcelle T, Joshua Y, et al. (2016) Association between Alcohol Consumption and Smoking to Predisposing Conditions: Health Fair Study in Dominica. Amer Sci Res Jour Eng Tech Sci 21: 29-40.

28. Schuckit MA (2014) Recognition and management of withdrawa delirium (delirium tremens). N Engl J Med 371: 2109-2113.

29. O'Keefe JH, Bhatti SK, Bajwa A, DiNicolantonio JJ, Lavie CJ (2014) Alcohol and cardiovascular health: the dose makes the poison or the remedy. Mayo Clin Proc 89: 382-393.

30. Milne J (1999) Questionnaire: advantages and disadvantages. Learning technology disseminated initiative.

31. McCabe SE, Schulenberg JE, Johnston LD, O'Malley PM, Bachman JG, et al. (2005) Selection and socialization effects of fraternities and sororities on US college student substance use: A multi-cohort national longitudinal study. Addict 100: 512-524. 